\title{
Amish Education: A Synthesis
}

\author{
Cory Anderson ${ }^{1}$ \\ Adjunct Professor \\ Arts, Science, and Business Division \\ Ohio State Agricultural Technical Institute
}

\begin{abstract}
Amish education is one of the most researched subtopics in Amish studies. This article is a meta-analysis of the existing literature about Amish education, finding that most research discusses how the parochial school system functions to socialize students into the broader Amish social system. In particular, the school socializes students into (1) several major Amishdefining internalized dispositions, ideologies, and outlooks and (2) the meso- and micro-level Amish social structure. Several anomalies do exist, including their educational approach to special needs children, parochial school dysfunctions, and alternative schooling methods. The article concludes with suggestions for future research, including more rigorous ethnographic studies that better divulge latent functions and the utilization of other theories to unlock other implicit patterns.
\end{abstract}

\section{Keywords}

Literature review; Meta-analysis; Parochial schools; Structural functionalism; Socialization; Ideology; Social structure; Ethnography; Separatism; Social networks; Mutual aid; Humility; Heritage; Dysfunctions; Special needs children; Wisdom; Symbols; Roles; School board; Teacher 


\section{Introduction}

Like few other subareas of Amish society, the Amish parochial school has held the fascination of Amish scholars. Indeed, more scholarship has been published about the parochial school than any other socialization process or domain among the Amish. By and large, scholars have approached the study of Amish schools from a structural functionalist tradition, which explores how parts of a society, like parts of a body, contribute to the whole. Accepted without debate, research consistently finds that Amish parochial schools reinforce the Amish social system (Harroff 1998; Hostetler 1970a; Hostetler and Huntington 1992[1971]; Johnson-Weiner 2007; McConnell and Hurst 2006). This theoretical tradition was initially and most emphatically articulated by John Hostetler and Gertrude Enders Huntington (1971). ${ }^{2,3}$ Put succinctly, Amish parochial schools are conceptualized as formal institutions (Gangel 1971) that socialize individual children into the community (Hostetler 1970b) by reinforcing Amish values and priorities (Hostetler 1975; Hostetler and Huntington 1992[1971]; Johnson-Weiner 2007) in a sort of community microcosm (Huntington 1994).

This structural functionalist emphasis is quite familiar to Amish studies. In fact, more Amish-focused research explores how a given societal component contributes to the strength of the total social system than any other driving idea. In an ongoing project that synthesizes Amish studies scholarship (Anderson 2012; Anderson 2014), I have identified four mutually reinforcing societal mechanisms that underlie the durability of the total social system. ${ }^{4}$ They are:

1. Population growth (growth $=$ births + conversion - defection - death),

2. Internalized ideologies, dispositions, and outlooks (e.g. Biblical literalism, traditionalism, separatism, common personality types, etc.),

3. Meso social structures (e.g. social networks, spatial configuration, and economy) and micro social structures (e.g. roles, language, and symbols).

4. Socialization processes (e.g. rituals, sanctions, “sowing wild oats,” technologies, care / concern, etc.) and domains.

Amish schools are one of three major socialization domains (along with family and community). Socialization domains and processes reinforce ideologies and social structures, which, in turn, enable the routine enactment of the social event "school." Amish schools began as a deliberate adaptation in response to broader change (Huntington 1994) and became what they are because the Amish want to accomplish specific ends (Fishman 1988). As such, schools are fitted to the peculiarities of the Amish social system (Hostetler 1970b).

Because of its effectiveness in reproducing the social system, parochial schools are by and large the preferred schooling option (Hurst and McConnell 2010; McConnell and Hurst 2006), evidenced by exponential growth: the number of schools doubled every decade across the 
$20^{\text {th }}$ century starting in the 1930s (Dewalt 2001). Parochial schools permit community control over educational processes (Schwieder and Schwieder 1975), epitomize Amish values (Kephart and Zellnar 1976), maintain continuity with home and community (Fishman 1988), and provide a selective introduction to the world while blunting its impact (Johnson-Weiner 2007). Amish schools are the most appropriate existing educational system for protecting children prior to their age of religious accountability (Hostetler 1970a) and may even be the Amish's most optimally functional institution, having ably weeded out the dysfunctions of the public school system (Friesen and Friesen 1996).

In depicting the functionality of parochial schools to the Amish social system, generalizations must be made, across time, place, and affiliation. At the same time, acknowledgement is made of diversity across these variables (Hurst and McConnell 2010; Johnson-Weiner 2007); to future research is the job of deciding how much or little each generalization is applicable to a given case. Nonetheless, cautious generalizations are by now merited, given the current body of literature captures well the categories of diversity, both within works that address many school settings (Dewalt 2006; Hostetler and Huntington 1992[1971]; Johnson-Weiner 2007) and across works that intensely focus on a local area / school (e.g., Enninger (1987) for Dover, DE; Fisher and Stahl (1986) for Lancaster County, PA; Fishman (1988) for central Pennsylvania; McConnell and Hurst (2006) for Holmes County, OH; and Harroff (2004) for Northern Indiana).

Further, this study only addresses the Amish education system as if it is a static system; a somewhat separate body of literature treats social change, or more specifically, the social conditions and historical events that brought about the change from public to parochial schooling. A second subtopic within social change in education is adaptation in the parochial school system since its establishment, but, unfortunately, no research has specifically investigated such changes, if any.

\section{Socialization into the Amish System of Internalized Dispositions, Ideologies, and Outlooks}

This first section synthesizes the ways in which the Amish parochial school system functions to socialize children into a set of internalized dispositions, ideologies, and outlooks that form the core Amish way of seeing the world. Subjects were identified from a meta-analysis of literature that identifies and interrelates dispositions, ideologies, and outlooks. While parochial schools do not reinforce every component of the total system, they do reinforce several core areas, as reviewed below.

\section{Wisdom vs. Critical Thinking and Science}

The Amish stress wisdom in education. The opposite of wisdom is not ignorance but critical thinking, an approach to knowledge inherent to the scientific method and the liberal arts (Littell 1969). In consolidated public schools, which the Amish object to, scientific and technical 
modes of thought direct students toward a specialty area and the employment of rational modes of addressing problems (Keim 1975; Meyers 2003[1993]). Conversely, wisdom privileges knowledge that is absolute and unchanging, universal and ethical. As an educational emphasis, wisdom is knowledge students inherit rather than discover. Wisdom-based learning is accomplished through an instructional method whose pedagogical tools focus on dissemination of collective thought through repetition, reenactment, and memorization (Littell 1969). As such, Amish teachers spend more time than public school teachers providing direct instruction versus indirect, which encourages critical thinking (Payne 1971).

In practice, the Amish method of learning involves students searching for and recording a single, correct answer rather than exploring the subjectivity of many possible answers (Fishman 1988; Hostetler and Huntington 1992[1971]). In reading assignments, for example, students are charged with recording the correct words, and a common meaning should be extracted from the text shared by all. In writing assignments, papers tend to hold much similarity; individual expression is minimized (though still present). Textbooks, especially reprints of outdated mainstream books, emphasize basic memorization (Johnson-Weiner 2008) over critical analysis. Math textbooks, for example, contain much review and avoid critical thinking and deepening methodologies (Oyabu, Ido and Sugihara 2002). Geography textbooks convey facts about places and people rather than map skills and scientific analysis of space (Oyabu and Sugihara 2004). Science, if taught, involves memorizing terms, like body parts of a grasshopper (Ediger 1998); if not taught, it is learned from nature experiences at home or on the farm (Ediger 2003). Such pedagogical methods nurture similarities rather than differences (Smith 1961) unto the end of fostering group consensus, which provides security and a sense of belonging for members (Hostetler and Huntington 1992[1971]). Such methods also sacralize custom and place the burden of proof on the new rather than the existing, an inverse outcome of critical thinking.

\section{Christian Ethics}

The pursuit of wisdom coincides with Amish Christian-based ethics. Religion is not explicitly and formally taught, though hardly absent from Amish schooling (Dewalt 2006; Ediger 1997); its complete absence in consolidated public schools, however, is objectionable (Kraybill 2001; Meyers 2003[1993]; Stoll 1975[1965]). Amish schools have prayer, Scripture reading (Fisher and Stahl 1986), and, in the more progressive schools, devotions (Harroff 1998). Preset prayers and Bible reading are further encountered by upper grades in German instruction (Harroff 2004). Schools also make ample time for singing in the morning, and the children freely select religiously themed songs more often than secular (Elder 2014).

Teachers are aware of the temptation to cheat, which typically takes the form of copying or sharing answers. Rather than allowing students to grapple with temptation, teachers simply limit the opportunities to cheat, conditioning students to this ethic of honesty without having to learn the hard way (Harroff 2004). 
Textbooks affirm general ethics through two strategies: inclusion and omission. In Amish and Old Order Mennonite-produced publications, work and stories reflect typical scenarios in an Amish child's life and weave in moral lessons, teaching ethics by example (Harroff 2004; Hostetler and Huntington 1992[1971]; Johnson-Weiner 2008). Conversely, outside textbooks are screened; inappropriate content (e.g. greed, sports, entertainment, insurance, wealth, and accumulation) are removed and flashy, colorful texts are typically not used (Harroff 2004). While older secular textbook reprints like McGuffey's Readers have fewer problems (and do instruct students in some ethics), and are thus used in some Amish schools (Avenatti 1991), reoccurring complaints include patriotism and story outcomes where moralism is always rewarded (Hostetler and Huntington 1992[1971]), prompting many to switch to plain Anabaptist produced texts.

\section{Humility}

Humility is a virtue cultivated through several techniques. First, the ratio of listening weighs much more heavily on listening than in public schools. Because the demand for speaking is higher than available opportunities, students internalize their status / importance as level with others. They must wait for an opportunity to speak, speak softly, or prioritize what is and is not said (Enninger 1987; Harroff 1998; Payne 1971). Second, good work is affirmed (e.g. “correct”) rather than praised (e.g. "good job”) (Harroff 1998). Finally, the school board looks for a teacher exemplifying Amish values, including humility. The teacher thus serves as a positive role model (Harroff 2004).

\section{Respect for Authority}

A central principle in the Amish ideological system is respect of and submission to authority, which is enabled by a body of interrelated virtues including humility (vs. pride), selfdenial, meekness, yieldedness, and so forth. By lowly esteeming oneself, the individual is more receptive to the input and direction of the community and God, has a greater interest in helping and aiding one another, maintains an awe and reverence for the sacredness of God, and can more easily live a lifestyle of nonresistance.

The parochial school contributes to socializing children into this set of attitudes. While Amish society is authoritarian, members view leadership, including teaching, as granted from God, as a calling made known through the community. Leaders view their calling with a sense of inadequacy. With this humility, the community trusts that the leaders have the community's good in mind, endowing authority relationships with trust. This is exemplified in the student's view of the teacher (Fishman 1988). As Amish children are taught to respect adults and authorities (Gallagher 1994), the Amish teacher serves as a more appropriate role model than a non-Amish teacher, who is an adult but does not embody Amish values (Hostetler and Huntington 1992[1971]; Schwieder and Schwieder 1975). Indeed, the Amish teacher daily signals her worthiness of emulation through conformity in clothing, which in its slight differences from students' garb symbolizes her support of the church as a baptized member (Enninger 1987). 
Teachers not only command respect as students interact daily with this authority figure, but they also explicitly train students to respect authority in general. In the classroom from day to day, teachers are preoccupied with sanctioning the smallest signs of rebellion and self-will; such cases are handled quickly, either at the moment of offense or the same day if discipline would cause a class disruption (Harroff 2004; McConnell and Hurst 2006). Rules are strictly enforced, albeit with obvious love and concern (Hostetler and Huntington 1992[1971]). Teachers have a wide array of informal and formal techniques in administering discipline (Hostetler and Huntington 1976). Nonetheless, young teachers may have a more difficult time commanding respect because of their proximate age to the students, whereas the age of experienced teachers commands greater respect through interpersonal distance. The form of instruction-largely seat work - teaches children to obey and follow directions without being regularly monitored. Additionally, stories in Pathway readers repeatedly stress obedience to authority (Harroff 2004).

\section{Heritage}

The Amish interpret their heritage as a set of more-or-less repetitious lifecycles across the generations, a continuity supported by traditionalism and offspring retention and resulting in a sense of groupness based on common ancestry and shared genealogy. They view their existence as suspended between Christ's first and second appearances. As sectarians, they are backward looking, seeking restoration of the true church and valuing oral tradition that is a dialogue with the past (Littell 1969). They reject consolidated public schools' emphasis on science and technical competence because of its obsession with present findings that discredit the past and move the world in a progressive direction (Littell 1969; Stoll 1975[1965]).

Heritage is reinforced through intergenerational continuity. Continuity is evident first of all in textbooks. Because the same texts and lessons used by children were often used by parents, continuity exists across the generations (Johnson-Weiner 2008), true of both reprints of secular textbooks, such as those released by Gordonville Print Shop / the Old Order book society, and Amish-produced texts, such as those of Pathway. Among the former are McGuffey's Readers, whose archaic style suggests continuity with past generations (Enninger 1999; Johnson-Weiner 1997). Pathway readers, on the other hand, are more recent, yet carry over the McGuffey's Readers pedagogical method, also suggesting continuity (Enninger 1999). Selected social studies textbooks focus disproportionately on places and periods of particular interest to the Amish, such as Pennsylvania geography and colonial history (Oyabu and Sugihara 2004; Oyabu, Takamatsu and Sugihara 2003). Beyond textbooks, the entire mode of learning demonstrates continuity with the old rural U.S. schools, evidenced in similar instructional goals (basic content) and the way English is taught, as a second native Amish language rather than as a secondary language, as High German is taught (Enninger 1999).

Other means reinforce the idea of continuity. Teachers are selected among those who went through the parochial school system and are therefore prepared to enact the role of teacher according to how it was once modeled by others (Harroff 2004). Additionally, the building 
architecture, furnishings, and materials are relatively antiquated by today's public school standards, thus reminding students of heritage (Dewalt 2001).

\section{Separation from the World}

Amish parochial schools reinforce the dichotomy between "our world" and everything beyond as "the world." Because parochial schools permit the Amish to maintain their majority status in this institution (Smith 1961), many everyday reminders of the community's separation carry over to the school, including the enclaval spatial setting, group-defining dress, temporal setting (if offset from daylight's saving time) (Enninger 1987), low technology (Smith 1961) such as wood stove heat (Bachman 1942), and signification of the English language as a group language learned specifically to communicate with the outside (Hostetler and Huntington 1992[1971]; Johnson-Weiner 1993). Social studies textbooks stress separatism by omitting global politics and contemporary history (Oyabu and Sugihara 2004; Oyabu, Takamatsu and Sugihara 2003), while health textbooks prioritize physical issues relevant to the Amish lifestyle (e.g. nutrition, personal health, and family health) over social, emotional, and mental issues of importance to modern mainstream society (e.g. STDs, drugs, dangers in the natural environment, violence, and being home alone, etc.) (Oyabu, Ido and Sugihara 2001). Pathway readers build separation into stories by featuring scenarios common to Amish children's' lives (JohnsonWeiner 2008; Oyabu, Takamatsu and Sugihara 2007).

Amish find separatism a difficult ideal to maintain in consolidated public schools. Nationalistic emphases (Meyers 1994), the cultural / ideological influence of non-Amish peers (Bachman 1942; Kraybill 2001; Meyers 2003[1993]; Stoll 1975[1965]), and technological advancements not enjoyed at home (e.g. daily bus transportation, central heating, electric lights, and modern bathrooms) (Bachman 1942) undermine the separatist orientation of the Amish.

\section{Socialization into the Amish System of Meso and Micro Social Structures}

This second section synthesizes the ways in which the Amish parochial school system functions to socialize children into the social structures that order and shape interactional patterns. As in the previous section, subjects were identified from a meta-analysis of literature that links a number of meso social structures (e.g. networks, economy, and mutual aid) and micro social structures (e.g. roles and symbols).

\section{Social Networks}

The Amish social network is characterized by high density; parochial schools, one, evidence, and, two, reinforce this highly integrated interactional structure. The inverse of high density is specialization and fragmentation, exhibited in consolidated public schools by the impersonal, non-relational setting (Littell 1969; Meyers 2003[1993]) and diverse extra-curricular activities offered (Bachman 1942; Stoll 1975[1965]), both reasons Amish rejected such schools. Schools exhibit the unity of close networks in conversational word choice (first names and 
informal German pronouns are used), common dress (low negotiability of signified network position), positive tone in interaction and even discipline (Enninger 1987), the common inclusion of others (versus isolation) in free hand drawings (Hostetler and Huntington 1992[1971]), high attendance rates $(90 \%+)$ signifying the importance of participation in social institutions (Ferster 1983), and the hiring of teachers through word of mouth in the local community or through teachers noticing older students with potential (Hostetler and Huntington 1992[1971]).

Intimate networks are in turn reinforced by the school, especially in regards to its size. By remaining small, the institution sits within walking distance of patron households. Such localism enables high social connectivity among parents, frequent interaction of students outside of school, and ease of family-school interaction (Bachman 1942; Dewalt 2006; Smith 1961). Indeed, from the school's beginning, the immediate neighborhood is responsible for constructing the school. Thereafter, the school board is the primary responsible body, and yet the neighborhood remains involved and invested in maintaining the building and supporting daily operations (Harroff 1998; Hostetler and Huntington 1992[1971]; Johnson-Weiner 2007), such as getting involved in leisure activities and attending school programs (Dewalt 2006). Small schools also enable teachers to guide student activities and intercept clique formation (Harroff 2004).

\section{Spatial Configuration}

Amish strive to create spatial enclaves; enclaves support optimal control over socialization processes. By not providing motorized transportation, each school must be within a walkable distance of all students (Dewalt 2006; Ferster 1983). Thus, the parochial school is a centripetal force on Amish residential location. In addition, by being in the center of the community, the school is situated in a physical setting that in many small ways reinforces community values and experiences (Harroff 2004).

Amish object to public schools when small rural schools were consolidated into larger schools in population centers. The school's removal from the immediate community was one of the key events that prompted many established Amish communities to switch to parochial schools (Dewalt 2006; Hostetler 1975; Hostetler and Huntington 1992[1971]; Kraybill 2001; Meyers 2003[1993]).

\section{Material Economy}

A manifest function of Amish schools is training for lifelong labor that builds material resources within families and community, which in turn contributes to systemic stability as needs are met. True to their agricultural roots, most Amish are generalists that hone their experience to a given manual trade. From schooling, they demand basic skills upon which they can build hands-on experience. Amish schools thus emphasize reading, writing / penmanship, and mathematical competency, skills used in adult Amish life (Bachman 1942; Dewalt 2006; Ferster 1983; Harroff 2004); for example, math textbooks stress "numeral and formulas” topics 
disproportionately, and in eighth grade students may do additional work in "life" and “agriculture” (Oyabu, Ido and Sugihara 2002). These three primary subjects are approached with vigor in the first two grades, then built upon in the middle grades. Building on foundational math techniques, upper grade students apply math skills to practical tasks, such as tax preparation, bookkeeping, problem solving, graphing, and geometry. Reading and writing also helps students develop literary skills needed in life. Notably, students learn English in order to interact with the outside world, especially in business transactions (Hostetler and Huntington 1992[1971]; Johnson-Weiner 1993; Oyabu, Takamatsu and Sugihara 2007). In early grades, teachers take students aside for focused instruction; each student reads in turn. Young students have the added challenge of being more familiar with Pennsylvania German than English when they start school. In middle grades, students take turns reading from their desks rather than being pulled aside; the teacher's oversight is slightly less, symbolizing gradually granted autonomy in work (Harroff 2004). In standardized testing comparisons between Amish parochial school students and nonAmish public school students, educational outcomes as measured by standardized tests typically rate higher for math, spelling, and word usage while lower for reading and vocabulary (Ediger 1986; Hostetler 1969).

Modeling — and thereby preparing students for — a typical adult work day, students put in the most concerted effort in the morning classes, tackling the three core subjects, while lighter workloads and subjects are pursued in the afternoon (Harroff 2004). These other subjects are introduced from fourth grade on, but are generally not seen as priorities (Harroff 2004). For example, in social studies, students learn about their local region and other cultures, skills helpful for their future work, but not as foundational (Oyabu and Sugihara 2004). Health instructs in hygiene, body parts, nutrition, and good life habits, again helpful, but not central learning goals (Harroff 2004; Oyabu, Ido and Sugihara 2001). Because the manifest goal of Amish education is to train children in practical skills for life, only elementary subjects are taught; extracurricular activities are not offered (Smith 1961).

Some schools - notably those in Pennsylvania-hold vocational classes for students who have passed eighth grade but are not of legal age to discontinue formal schooling. A typical vocational program requires students to journal their weekly work and to attend school one day a week (Dewalt 2006). Journals tend to focus on factual statements of work done, not personal reflections, signaling that work is about functioning in an existing occupational sphere that does not include innovative, creativity-based professions (Fishman 1988). Vocational schools transition students from school to adult-level work: when to work, how to fill a work role, how tasks are managed, and how work contributes to the community (Hostetler and Huntington 1992[1971]).

In addition to actual skills, the school, by treating school work like adult work, instills in students an active work ethic. This ethic has four emphases First, students are taught to value and enjoy work through reading lessons that emphasize enjoying school (Harroff 2004) and through the admonition of the teacher (Gallagher 1994). In one study, freehand drawing exercises of a 
"happy time" included many work activities, while "job” drawings included farming or service oriented activities that showed a love for realistic work (Hostetler and Huntington 1992[1971]). Second, students are taught to work hard (Ediger 2005). The core subjects especially are framed as hard work (Harroff 2004), and students are taught to put in whatever effort is required to solve each problem encountered. School is work, and as such is not peppered with frequent fun activities and little rewards as incentives (Dewalt 2006). Third, teachers admonish students to do their work carefully, especially as they complete their lessons (Avenatti 1991; Harroff 1998; Schwieder and Schwieder 1975). Where Amish students in one study did not do as well in a standardized reading test as their public school counterparts, it was found that they did well on the questions they answered, but did not complete the test in time (Hostetler and Huntington 1992[1971]). Fourth, students are taught to take initiative and responsibility for their work (Smith 1961), which is achieved in part by students needing to work alone (as the teacher is rarely available to answer questions) and by the gradual transition of responsibility (Dewalt 2006) through vocational schools, which grant greater autonomy in work (Hostetler and Huntington 1992[1971]). Amish want to move children into the realistic work world in their early to mid-teens, and thus object to the idea of prolonged schooling embraced in consolidated schools (Hostetler 1975; Hostetler and Huntington 1992[1971]; Kraybill 2001).

\section{Organizational Scale}

Given the low student numbers, the Amish parochial school contributes to the character of Amish organization as small-scale. The school is operated by an intimate school board (often three-man) and the number of teachers in a single school typically ranges from one to four. In rejecting consolidated public schools, Amish objected in part to the growing bureaucracyhierarchy and organizational complexity - that undermined local authority and small scale units (Hostetler and Huntington 1992[1971]; Keim 1975; Meyers 2003[1993]).

\section{Mutual Aid}

Mutual aid is a symbolic economy of material and non-material resource exchange and redistribution, which currency is backed by community trust and reciprocated concern (this concept shares much in common with "social capital"). The opposite of mutual aid is competition, which Amish try to minimize. Indeed, Amish object to consolidated public schools partly because of an emphasis on individualistic competition (Meyers 2003[1993]).

The childhood stage of life is an important time for the young to learn to depend on the community (Hostetler 1970b), and the parochial school system contributes to the mutual aid system by socializing students into this economy of cooperation. The teacher instructional style entails leading children in a setting of low competition and high cooperation. First, the teacher is aware that ill-feelings can arise out of competition over good grades or cliquishness on the playground, so she carefully monitors student behavior and addresses budding competition quickly (Harroff 2004). Second, because the teacher cannot respond to the high demand for 
assistance, she frequently permits older students to help younger students and the more able to help the slower; this lowers competition and cultivates a sense of cooperativeness and concern for others (Dewalt 2006; Hostetler and Huntington 1992[1971]; Schwieder and Schwieder 1975). Finally, Pathway readers make concern for others a frequently reoccurring theme in their stories (Harroff 2004). The sum impact is that children are taught to operate out of concern for others rather than fear of punishment (Gallagher 1994). In this voluntarily cooperative environment, students need not fear being singled out (Dewalt 2006) or mocked for inability (Hostetler and Huntington 1992[1971]).

The parochial school contributes to the broader Amish social system of mutual aid in at least two other ways. First, because schools are small and private and the teacher-to-student ratio is low, teacher pay is not enough in itself to make it. This provides opportunities for the community to show their support through housing arrangements and / or donations (Harroff 2004). Second, the smallness and interpersonal intimacy of the parochial school makes it easier for teachers, students, and parents to surprise each other throughout the year, especially on birthdays or special occasions (Fisher and Stahl 1986).

\section{Language}

A primary function of Amish education (and secular education as well) is the enabling of meaningful participation in the adult world. For sectarian Protestants like the Amish, this means participation in a Christian life among a people who stress personal relations (Littell 1969). While Amish children learn Pennsylvania German at home as their primary language, English is taught with concerted effort in school. To participate in community life, everyone must understand English, as much English communication is transmitted in written form, whether in communications with the broader world or in group-specific literature (Fishman 1988).

Of the three major domains where English is taught, the school subjects children to the most guidance. Thus, by taking a forefront role in training students in literacy, the school functions to enable a foundational form of oral and written meaning-making (Fishman 1988). English is not treated like a second language even though to many children it is. Rather, English instruction is approached similarly to public schools, where English is the first language of students, and is also taught indirectly in other subjects. As students go through school, English becomes a second first language (Enninger 1999). However, the English that is learned treats it as of the world's system (Hostetler and Huntington 1992[1971]; Johnson-Weiner 1993; Oyabu, Takamatsu and Sugihara 2007); Pennsylvania German is still preferred for the most intimate, ingroup specific conversations.

High German is important for reading the Luther Bible, understanding prayers, and, in more conservative churches, understanding portions of the church service not in Pennsylvania German. However, as a subject taught explicitly and as a relatively new instructional innovation, High German is generally the weakest of all subjects taught (Enninger 1999). 


\section{Symbols}

The parochial school socializes the Amish child into the nuanced world of Amish symbols. Being in Amish-only schools, students are immersed in an Amish-specific communicative system daily. Because speech in the classroom is an in-demand commodity, students must claim a speaking role through non-verbal ways. While teachers work audibly with a given grade, they also manage the communicative system. Visual cues are exchanged between teachers and marginal groups through writing on the chalk board, gesticulating permissions, and audibly replying in brief to student requests. The by-necessity quietness of Amish classrooms accustoms children to detecting and transmitting subtle nonverbal signals that permeate much of Amish life. Students also remain attuned to subtle symbolic meanings of relatively small clothing signals by daily interacting with similar others, including what grooming and garment patterns symbolize a church member, as displayed by the teacher (Enninger 1987). Daily encounters with settlement- and subgroup-specific symbols like clothing, but also school building architecture and technology usage, further trains students to recognize other Amish affiliations through symbolic differences (Harroff 2004).

\section{Roles: Teacher and School Board Member}

The parochial school system facilitates two major roles that otherwise would not exist: the Amish parochial school teacher and the school board member. Given the emphasis on ascribed roles ${ }^{5}$ and the general withholding of formal leadership positions from women, it is of interest that most teachers are female. The school teacher is the most constant and visible formal leadership position available for women, albeit still legitimized by a male school board (McConnell and Hurst 2006). All status-enhancing formal leadership positions in the Amish community, including "teacher," are imbued with spiritual connotations, as they are looked to as an example of ideal behavior (e.g. cooperativeness, willingness to help, diligence, and obedience) (Hostetler and Huntington 1976). Thus, like other formal leadership positions, the teacher is selected in part based on her overall life habits and support of the church (Hostetler and Huntington 1992[1971]). Amish object to consolidated public schools because the teachers do not embody Amish values and therefore cannot serve as role models (Hostetler 1975; Hostetler and Huntington 1992[1971]; Kraybill 2001; Littell 1969; Stoll 1975[1965]).

To perpetuate the role of "teacher" to all who seek to fill it, a system of resources and networks is available to socialize the individual into the role and then to keep teachers abreast to developments in the profession. Though familiar with the parochial school system through experience, first-year teachers still have a steep learning curve, as they are typically young and only eighth grade educated (Harroff 2004). Some teachers bring to their first year apprenticeship experience from their final student years (Hostetler and Huntington 1976; Schwieder and Schwieder 1975). Nonetheless, new teachers spend many extra hours reading through teachers' guides provided by plain publishers. These guides—addressing basic classroom, instructional, and administrative topics—are much more thorough than their secular counterparts; if followed 
directly, they leave little to chance (Harroff 2004).

Beyond initial socialization into the teacher role, ongoing training solidifies the role of teacher by creating networks of teachers, bringing professionalism to the field (Hostetler and Huntington 1992[1971]) and providing a forum for teachers to raise and respond to new challenges (Fishman 1988). Teacher-focused publications, notably Pathway's Blackboard Bulletin, feature moral stories, real-world problems, question and answer sections, advice, and teaching philosophies. Regional teachers' meetings provide timely topics, question and answer sessions, and network-building opportunities (Dewalt 2006; Fisher and Stahl 1986; Fishman 1988; Harroff 2004; Hostetler and Huntington 1976; Hostetler and Huntington 1992[1971]). Informally, feedback from other local teachers, students' parents, and the school board further hones what it means to successfully fill the role of "teacher" (Dewalt 2006; Hostetler and Huntington 1976). A few teachers also engage in non-Amish correspondence courses (Harroff 2004).

School board members are commonly selected from school children's parents. School board members administrate the school, as with hiring teachers, managing finances, keeping attendance records, and solving major conflicts (Fisher and Stahl 1986; Hostetler and Huntington 1992[1971]). The school board is responsive, though not accountable to, the standards set forth by the National Steering Committee, which represents the schools to the national government (Ferster 1983). Beyond descriptive accounts, no conceptual research explores how the school board member role socializes Amishmen into societal structures and ideologies.

\section{Anomalies in the Educational System}

Parochial school functionality in the Amish social system, as described above, is a generalization across many settlements and the history of Amish parochial schools. Despite its broad functionality, Amish education holds three anomalies: the integration of special needs children (a minority) into the system, dysfunctions of Amish parochial schools, and alternative, competing educational options to the parochial school system.

\section{Special Needs Accommodations in Amish Parochial Schools}

Special needs students are a minority population whom Amish parochial schooling in its standard form is not specifically designed to wholly accommodate. Nevertheless, Amish parochial schools do make some provisions for mild special needs cases, which may include seating next to the teacher's desk, a side partition or additional classroom with a separate teacher devoted to these students, or, in larger settlements, an entire parochial school dedicated to special needs students. Accommodations have been slow in coming, which Amish may view as a weakness of their schools compared to public schools (Newcomb 1986). In making accommodations, Amish schools' goals are to, one, protect these students from the influence of the public school system (thus contributing to the Amish belief in separatism), and, two, provide individualized attention (thus contributing to the Amish practice of care). However, the extent 
varies to which effort is made to include them in regular classroom activities and give them the same curriculum used by other students (Dewalt 2006; Fisher and Stahl 1986; Harroff 2004; Hostetler and Huntington 1992[1971]). Amish children with severe handicaps will typically attend public school.

\section{Dysfunctions of Amish Parochial Schools}

The bulk of Amish parochial school research focuses on the way the school is functional in socializing students into societal ideologies and structures. However, five areas of dysfunction are also mentioned. In general, though, as Hostetler and Huntington (1992[1971]) observe, school problems are often symptomatic of community problems.

First, schools have difficulty coping with teacher turnover, especially among young females. Both the low pay (functional in other ways, as discussed above) and the status enhancing rite of passage from day-laborer to wife / mother contribute to the turnover, which lends a measure of instability and discontinuity to school leadership (Dewalt 2006; Harroff 2004; Hostetler and Huntington 1992[1971]).

Second, while young parents pay for local public schools through taxes, they have the added expense of supporting a parochial schools - teacher salaries, the building, textbooks, etc. - at a time in life when income is particularly needed, providing some hardships for poorer young families. Conversely, minimal financial support of a school, which may or may not be a product of the number of low income families supporting the school, creates problems in teacher retention, building adequacy, and curriculum quality (Harroff 2004; Hostetler and Huntington 1992[1971]).

Third, schools vary in quality: teacher personality, curriculum, social classes represented (McConnell and Hurst 2006), financial resources, school board quality, and parental support (Hostetler and Huntington 1992[1971]). These differences have the potential to produce distinct socioeconomic classes in a generation that can militate against the emphasis on community levelness (McConnell and Hurst 2006).

Fourth, while parent-teacher relationships are generally healthy, strained relationships are not uncommon. Because the teacher is a leader and example to the students, the underlying root of otherwise trivial conflicts is often parental disapproval of a teacher's example, arising itself from diverse outlooks on ideals. Students feel the stress of conflict, leading to poorer socialization outcomes (Hostetler and Huntington 1976). School boards are charged with mediating these conflicts, though in some cases the school board may actually exacerbate the conflict (Hostetler and Huntington 1992[1971]). Another possible source of parent-teacher stress is over the amount and frequency of homework, which is a conflict over the extent of the school domain's presence in the home (Harroff 2004); many, though not all, communities informally agree on a homework policy 
Finally, while curriculum is one of the strongest components of the parochial school socialization process, curriculum may have dysfunctions that cannot be circumvented. For example, students using McGuffey's Readers may receive inadequate reading exercises because the texts are boring and antiquated. Pathway readers, on the other hand, are higher quality and more relevant to Amish life, yet in those very traits may accustom students to treating English as a language capable of addressing in-group challenges (Johnson-Weiner 1997).

\section{Alternative Forms of Schooling}

In several very old settlements (including Holmes County, OH; Northern Indiana; and Oakland, MD), some families send their children to public schools. ${ }^{6}$ Most research has focused on Holmes County, $\mathrm{OH}$, which hosts five exclusively all-Amish public elementary schools and several mixed public schools (McConnell and Hurst 2006). Here perhaps more than anywhere else, the Amish have retained influence in local affairs, and, consequently, many have stayed with the local public schools (Hostetler and Huntington 1992[1971]). Though the majority supports parochial schools, the longstanding relationship with public schools is not easily uprooted. Leaders have generally remained silent on this issue (Hurst and McConnell 2010). ${ }^{6}$ The reasons some parents opt for public over private schools include the belief that public schools provide better instructional quality, the public school actively solicits and is willing to work with the Amish, and the opportunity for Amish students to interact with non-Amish, as they increasingly must do in the adult world (Hurst and McConnell 2010; McConnell and Hurst 2006). Findings differs over whether (Harroff 2004) or not (McConnell and Hurst 2006) parents opt for public schooling because of the cost associated with parochial schools.

Two studies suggest a less successful socialization outcome for public schooling than parochial schooling. In an earlier study, Loomis and Jantzen (1962) administered a personality test to four groups of students: Amish and non-Amish in mixed and non-mixed settings. They found evidence of system convergence in the mixed setting among Amish and non-Amish students. The Amish in the integrated school come a little closer to matching the non-Amish in the integrated schools than their parochial school counterparts; social boundaries between the two groups lower over time with integration. In a more recent study in Northern Indiana, Meyers (1994) found that public school attendance was correlated with a higher chance of defection, though the correlation could be a product of households predisposed to defection disproportionately sending their children to public schools.

On the other hand, a recent study of a Holmes County public school consisting of $40 \%$ Amish attributed high math scores on state-wide tests to (1) a collectivist ethos inclusive of all economic classes, (2) community ownership of and involvement in the school, (3) affirmation of local culture in stressing conservative, agrarian values rather than esteeming middle class values as an ideal for which to strive, (4) hands-on math that involved more problem solving than evident in other state public schools, and (5) the "other" population (Amish) being accepted (Howley et al. 2008). While public schooling overall appears to be an inferior mechanism for 
socializing Amish children, nevertheless, public schools sensitive to integrating Amish ideologies and structures may come out all the stronger, dissolving into the public educational system what elements make the Amish social system itself durable and integrated.

Homeschooling is a seldom taken educational approach, limited to the first families in a new settlement and a minority of New Order Amish / New Order Christian Fellowship families. New Order parents may opt for homeschooling because it strengthens the connection between children and parents, gives parents more control over the quality of their children's education, and grants parents more opportunity to monitor influences in education. Critics believe it isolates the family from the community and nurtures a "know-it-all" attitude (Hurst and McConnell 2010; McConnell and Hurst 2006).

Additionally, Holmes County, Ohio, does not have Pennsylvania's vocational schools, and the church remains firmly against full-time schooling after age 14. Consequently, some teenagers, particularly those from progressive Old Order families, pursue vocational courses, trade certification, and even GEDs as they prepare for more specialized career prospects than their conservative counterparts (Hurst and McConnell 2010; McConnell and Hurst 2006).

\section{Discussion}

In summary, the current body of literature argues that the Amish parochial school is an effective institution in supporting and reproducing the total Amish social system through socializing children into the thought process of internalized dispositions, ideologies, and outlooks and the meso and micro social structure. While a review of the literature may suggest the subtopic is saturated, if not repetitious at this point, this mirage exists because of the obelisk theoretical approach to understanding Amish schools. While structural functionalism is a widely used and useful theoretical lens, perhaps even the most appropriate, the literature is experiencing inertia because it is (1) enabling the "Amish schools as quant” myth, (2) presenting largely descriptive accounts that always assume positive integrative functions of schools for Amish society but make few theoretical / conceptual claims, and (3) condoning methodological sloppiness, as everything is "ethnography" yet does not report any data collection procedures, coding / data analysis schemes, or researcher reflexivity.

What emerges then is tautological research, that is, what exists, exists because it is functional to the culture, a logical flaw in that it is circular reasoning that cannot be empirically falsified. Education research easily falls into this trap where observations and interviews capture only manifest functions, those conscious, deliberate intentions on the part of those involved in the system. In essence, much research has simply reported to the scholarly community what a few Amish think of their system, as related in conversations and interviews. However, subjects are, in some cases, the least able to articulate the "whys" of why things are as they are. Hence, much of the social sciences' intrigue is in discovering latent processes about which actors are not aware. 
Two gifts to Amish studies are notable exceptions of strong ethnographic studies. Both studies employ ethnography with such rigor that they unearth processes of latent functionality. First, Werner Enninger (1987) uses an "ethnography of communication” method and framework to interpret the meaning of interactions in an Amish school. "Ethnography of communication" argues that rules and contexts bound the exchange of meaning. Communication is goal-oriented and work that requires skill. Social life, then, is a signaling system of implicit, de facto norms; patterns observed are signs that represent something. Put in his words, “The observable behavioral patters are signifiers whose signifieds are the orientation, values, and norms of the culture which has organized its interaction system and its signaling system in the manner that it actually has" (147). From this theoretical and methodological basis, he documents patterns of interaction in the classroom and derives meaning from these patterns with refreshing (though all too brief) depth.

Second, Andrea Fishman (1988) approached her study of an Amish-Old Order Mennonite school from an ethnographic perspective. She argues that ethnography allows the researcher to be in another culture, to try to see the world through their eyes, to understand their practices and beliefs, and to develop personal relations that facilitate understanding. In the first chapter, she justified her decision with the following rationales: (1) she did not want to treat Amish like a museum: "Amish are distinct individuals who intentionally choose to maintain their shared appearance" (7); (2) she sought "thick descriptions" whereby she could discover the humanity and complexity of the Amish; (3) she was studying the school along with other social spheres, and ethnography permitted her to study each without forgetting the others; and (4) she already knew the people under study, and this approach kept her from reducing the quality of these relationships for the sake of research. To her key informant, she was already a friend. To the teacher, she was a co-teacher with an outsider's perspective, not an outside teacher. Day in and day out, she carried her notepad with her to record conversational snippets from in the classroom to around the sink after supper. Through much patience, her intense research yielded its most conceptual results near the end of her study, which abruptly ended (see 70-72). Similarly, her categories of analysis came together only after much time spent in coding experimentation. Fishman's highly nuanced and descriptive research accomplishes all four of her rationales, notably avoidance of the "museum" outlook-fascinating spectacles to record like field biologists describing a grasshopper. Fishman's account stands among the best qualitative research in Amish studies and is a testament to the quality of a full-scale ethnography, where data and findings re-inform the researcher's predetermined outlooks on the culture.

Returning to the overly functionalist nature of Amish education research, this very orientation should also be questioned. Comparing the Amish to other plain Anabaptist groups suggests that parochial schooling is not a necessity to retaining a distinctive / separatist expression of Anabaptism. While some plain Anabaptist groups have also made parochial schools the normative mode of education-notably the Old Order Mennonites, conservative Mennonites, and Amish-Mennonites — other groups remain viable without depending on 
parochial schools. This throws into question how much the numerous functions of Amish parochial schooling actually contribute necessarily to socializing the young or is simply a set of facile conjectures relying on face value logic for support but could actually be another way. Most Old German Baptist Brethren and related Old Order-oriented Brethren affiliations have continued with the public school system even after school consolidation. Indeed, those Brethren establishing parochial schools may be viewed as innovative and progressive. Most Hutterites have a colony school that is staffed by the public school system. Like the Brethren, those Hutterites establishing on-colony parochial schools funded and staffed by their people are often considered innovative and progressive. Apostolic Christians have also long patronized public schools, even through consolidation, though it is common to find mid-sized Apostolic schools in the larger settlements, like the Rittman-Smithville, $\mathrm{OH}$, and Peoria-Eureka, IL regions. These schools are an option, not a requirement or even community preference, and the mix includes both conservative and liberal Apostolic schools. A minority of Apostolic families also home school. The Bruderhof (Arnold colonies), on the other hand, privileges the community over family and individual to a degree greater than other plain Anabaptists. Fittingly, they have a farreaching educational program that begins in infancy and is staffed by college educated Bruderhof teachers. More recently, high school-age students began attending a boarding school in one New York colony. Inversely, the Remnant churches (“Charity”) stress family above and beyond community, so their preferred schooling method is, appropriately, home schooling.

If we argue that what educational choices these groups have made are functional to achieving child socialization into separatist Anabaptism, then we can rightly ask if parochial schooling is indeed the only or most ideal option for Amish. This challenge gets its proverbial foot in the door because of the tautological assumptions of prior research (what is in Amish education exists because it is functional). Alternatively, if parochial schooling is truly the most effective means to cultivating separatist Anabaptism in the next generation, do we then assume that the educational modes other groups employ are dysfunctional where their execution contains elements mutually exclusive to the Amish educational system? Such questions call for the insights of comparative research.

An alternative theoretical direction to structural functionalism is a conflict perspective. The literature alludes briefly to clique formations and some difficulties between teachers and parents. As well, if schools are a microcosm of the total community, to what extent, then, are they still functional when community relations are strained? Second, as parochial schools change over time, what is the source of change and what types of people do the changes privilege? Finally, in Holmes County, OH, and Northern Indiana, where Amish students are split between public and private schools, what sort of disparities underlie this difference, if any, and what longterm differences are coming out of these competing socialization processes? Another theoretical perspective comes from the rational choice school of thought. If schools were merely an institution on which the Amish sought control, could the sheer monopoly most Amish communities now have on their schooling reduce the quality of program offered to students, 
whereas when the schools had to compete with the threat of public schools (pre-Yoder), the community may have made a more concerted effort to offer an orderly, strong program that discredits the claims of the public schools that the Amish offering is inferior?

\section{In This Special Issue about Anabaptist Education}

In this special issue of JAPAS, three researchers take on new directions in the relationship between the Anabaptists and schooling, each in a different way questioning the conclusion that Anabaptist schools are completely functional.

In Karen Johnson Weiner's article, she addresses changes in the Amish parochial school system since the Yoder decision that symbolically legitimized their private schools. She argues that the Yoder decision was made in part on two contradictory facts: that Amish need their own schools to maintain their separatist culture, and that Amish schools achieve similar educational outcomes as public schools. Yet, the schools that perform well on tests are most likely the progressive schools, whereas the separatist schools do not make it their objective to measure up to such outside standards of achievement. With the autonomy granted to Amish schools after Yoder, the divide between conservatives and progressives is expected to grow, and their educational systems will reinforce this growing disparity.

Daniel Ziegler, former president of the Conservative Mennonite Conference's Rosedale Bible College, compares the outcome of CMC young adults attending public universities to those attending the denomination's Bible College. He finds that the College is not completely achieving denominational goals in socializing young people but has mixed outcomes: while RBC attendees have higher levels of church attendance than public university attendees, they also have lower levels of civic volunteerism.

Finally, Janelle Zimmerman, a nursing student and member of the Groffdale Mennonite Conference, compares Old Order Mennonite and Hutterite parochial schools. Her comparative study identifies several shared functional elements, satisfying in a preliminary way the call here to engage in comparative research.

With the diverse research presented in this issue, scholars of plain Anabaptist education have much to reconsider as they ponder future contributions to this subfield.

\section{Endnotes}

${ }^{1}$ Contact information: Cory Anderson, japas@beachyam.org

${ }^{2}$ Much of the study was based on an Office of Education-sponsored research report (Hostetler 1968; Hostetler 1969) addressing parochial school structure, stages of Amish life, achievement test outcomes, and traditional versus "emergent Amish.”

${ }^{3}$ Littell’s (1969) "little” known conference paper was printed two years prior and arguably out- 
theorized Hostetler and Huntington. Donald Erickson, in the conference proceeding's introduction, called it "the most luminous explanation I have seen of the Amish educational posture" (2-3), and, in my opinion, still ranks among the best. Unfortunately, the work is undercited.

${ }^{4}$ This part of the theory accounts for the static system, while a second part, not discussed here, accounts for social change that alters this system.

${ }^{5}$ Ascribed roles are based on status attributes that you cannot change about yourself e.g. those based on gender, age, God's calling, etc.. These are in contrast to achieved roles, those secured as a product of what one has made of himself, e.g. education, sociability, wealth, etc.

${ }^{6}$ From January through March 2015, the Daily Record newspaper of nearby Wooster, OH, featured three front-page articles about new wireless handheld technologies being implemented in east Holmes schools, both in all-Amish schools and mixed schools. A letter to the editor I wrote in reply (April 8), which questioned the value of these developments, prompted phone calls from local Amish leaders and laity. From these conversations, I am left wondering if this finding is still true, or at least how long it will remain true if it still is. I am told at least one bishop now makes public school attendance a test of membership in his district.

\section{References}

Anderson, Cory. 2012. "Why Have the Amish Survived?” Presented at the Annual Conference of the Society for the Scientific Study of Religion and the Religious Research Association, November 9-11, 2012. Phoenix, AZ.

Anderson, Cory. 2014. "Why Have the Amish Survived? A Synthesis.” Kreider Lecture. Presented at the Young Center for Anabaptist and Pietist Studies, Elizabethtown College. March 20, 2014. Elizabethtown, PA.

Avenatti, Linda. 1991. “Qualitative Study of an Amish School.” Contemporary Education 62(3):199-201.

Bachman, Calvin George. 1942. The Old Order Amish of Lancaster County. Norristown, PA: Pennsylvania German Society.

Dewalt, Mark. 2001. “The Growth of Amish Schools in the United States.” Journal of Research in Rural Education 17(2):122-24.

Dewalt, Mark. 2006. Amish Education in the United States and Canada: Rowman \& Littlefield Education.

Ediger, Marlow. 1986. "Education among the Amish.” Multicultural Education Journal 4(2):49. 
Ediger, Marlow. 1997. "Examining the Merits of Old Order Amish Education.” Education 117(3):339-43.

Ediger, Marlow. 1998. “Teaching Science in the Old Order Amish School.” Journal of Instructional Psychology 25(1):62-66.

Ediger, Marlow. 2003. “Science Learning from Farming: The Old Order Amish.” The Hoosier Science Teacher 28(3):87-91.

Ediger, Marlow. 2005. “Old Order Amish Philosophy of Education.” Education 125(3):422-25.

Elder, D.R. 2014. Why the Amish Sing. Baltimore, MD: Johns Hopkins University Press.

Enninger, Werner. 1987. “On the Organization of Sign-Processes in an Old Order Amish (O.O.A.) Parochial School.” Research on Language and Social Interaction 21:143-70.

Enninger, Werner. 1999. "Continuity and Innovation in the Bilingual Education among the Amish.” Pp. 213-24 in The Construction of Knowledge, Learner Autonomy and Related Issues in Foreign Language Learning: Essays in Honour of Dieter Wolff, edited by Bettina Missler and Uwe Multhaup. Sonderdruck: Stauffenburg Verlag.

Ferster, Herbert. 1983. “The Development of the Amish School System.” Pennsylvania Mennonite Heritage 6(April):7-14.

Fisher, Sara, and Rachel Stahl. 1986. The Amish School. Intercourse, PA: Good Books.

Fishman, Andrea. 1988. Amish Literacy: What and How It Means. Pourtsmouth, NH: Heinemann.

Friesen, Bruce, and John Friesen. 1996. Perceptions of the Amish Way. Dubuque, IA: Kendall/Hunt Publishing Company.

Gallagher, Thomas. 1994. “The Old Order Amish.” Pennsylvania Folklife 43(1):98-105.

Gangel, Kenneth. 1971. “The Amish of Jamesport, Missouri.” Practical Anthropology 18(JulyAugust):156-66.

Harroff, Stephen Bowers. 1998. "Value-Oriented Teaching in a Contemporary Indiana Amish Parochial School: Preparations for Adult Life through Faith, Responsible Behavior, and Community Interaction.” International Journal of Educational Reform 7(3):243-54.

Harroff, Stephen Bowers. 2004. The Amish Schools of Indiana: Faith in Education. West Lafayette, IN: Purdue University Press.

Hostetler, John A. 1968. “The Amish Socialization Study: A Research Project.” Mennonite Quarterly Review 42(1):68-73. 
Hostetler, John A. 1969. Educational Achievement and Life Styles in a Traditional Society, the Old Order Amish. Final Report. Washington, DC: Office of Education (DHEW), Bureau of Research.

Hostetler, John A. 1970a. "Old Order Amish Child Rearing and Schooling Practices: A Summary Report.” Mennonite Quarterly Review 44(2):181-91.

Hostetler, John A. 1970b. "Socialization and Adaptations to Public Schooling: The Hutterian Brethren and the Old Order Amish.” The Sociological Quarterly 11(2):194-205.

Hostetler, John A. 1975. "The Cultural Context of the Wisconsin Case.” Pp. 99-113 in Compulsory Education and the Amish, edited by Albert Keim. Boston, MA: Beacon Press.

Hostetler, John A., and Gertrude Enders Huntington. 1976. "The Amish Elementary School Teacher and Students.” Pp. 194-205 in Schooling in the Cultural Context, edited by J.I. Roberts and S.K. Akinsanya. New York, NY: David McKay.

Hostetler, John A., and Gertrude Enders Huntington. 1971. Children in Amish Society: Socialization and Community Education. New York, NY: Holt, Rinehart, and Winston.

Hostetler, John A., and Gertrude Enders Huntington. 1992[1971]. Amish Children: Education in the Family, School, and Community. New York, NY: Holt, Rinehart, and Winston.

Howley, Aimee, Craig Howley, Larry Burgess, and Drew Pusateri. 2008. "Social Class, Amish Culture, and an Egalitarian Ethos: Case Study from a Rural School Serving Amish Children.” Journal of Research in Rural Education 23(3):1-12.

Huntington, Gertrude Enders. 1994. "Persistence and Change in Amish Education.” Pp. 77-95 in The Amish Struggle with Modernity, edited by Donald Kraybill and Marc Olshan. Hanover, NH: University Press of New England.

Hurst, Charles, and David McConnell. 2010. An Amish Paradox: Diversity and Change in the World's Largest Amish Community. Baltimore, MD: Johns Hopkins University Press.

Johnson-Weiner, Karen. 1993. "Community Expectations and Second Language Acquisition: English as a Second Language in a Swartzentruber Amish School.” Yearbook of German-American Studies 28:107-17.

Johnson-Weiner, Karen. 1997. "Reinforcing a Separate Amish Identity: English Instruction and the Preservation of Culture in Old Order Amish Schools.” Pp. 67-78 in Languages and Lives: Essays in Honor of Werner Enninger, edited by James R. Dow and Michele Wolff. New York: Peter Lang Publishing, Inc. 
Johnson-Weiner, Karen. 2007. Train Up A Child: Old Order Amish \& Mennonite Schools. Baltimore: Johns Hopkins University Press.

Johnson-Weiner, Karen. 2008. "Publish of Perish: Amish Publishing and Old Order Identity.” Pp. 201-19 in The Amish and the Media, edited by Diane Zimmerman Umble and David Weaver-Zercher. Baltimore, MD: Johns Hopkins University Press.

Keim, Albert. 1975. "From Erlanbach to New Glarus." Pp. 1-15 in Compulsory Education and the Amish, edited by Albert Keim. Boston, MA: Beacon Press.

Kephart, Williaam, and W.W. Zellnar. 1976. Extraordinary Groups: An Examination of Unconventional Life-Styles. New York, NY: St. Martin's Press.

Kraybill, Donald. 2001. The Riddle of Amish Culture. Baltimore, MD: John Hopkins University Press.

Littell, Franklin. 1969. "Sectarian Protestantism and the Pursuit of Wisdom: Must Technological Objectives Prevail?” Pp. 61-82 in Public Controls for Nonpublic Schools, edited by Donald A. Erickson. Chicago, IL: University of Chicago.

Loomis, Charles, and Carl Jantzen. 1962. "Boundary Maintenance vs. Systemic Linkage in School Integration: The Case of the Amish in the United States.” Journal of the Pakistan Academy for Village Development 3(2):1-25.

McConnell, David, and Charles Hurst. 2006. "No 'Rip Van Winkles' Here: Amish Education since Wisconsin v. Yoder.” Anthropology and Education Quarterly 37(3):236-54.

Meyers, Thomas. 1994. "The Old Order Amish: To Remain in the Faith or to Leave?” Mennonite Quarterly Review 68(3):378-95.

Meyers, Thomas. 2003[1993]. "Education and Schooling.” Pp. 87-107 in The Amish and the State, edited by Donald Kraybill. Baltimore, MD: Johns Hopkins University Press.

Newcomb, Thomas. 1986. "A Study of Amish and Conservative Mennonite Schooling in Ohio, 1982-1985.” Pp. 54-72 in Internal and External Perspectives on Amish and Mennonite Life 2, edited by Werner Enninger, Joachim Raith, and Karl-Heinz Wandt. Essen, West Germany: Unipress.

Oyabu, Chiho, Miyuki Ido, and Toshiharu Sugihara. 2001. "Amish Education 1: Analysis of Health Textbooks." Annual Report of the Faculty of Education, Gifu University, Educational Research 3:129-50.

Oyabu, Chiho, Miyuki Ido, and Toshiharu Sugihara. 2002. "Amish Education 2: Analysis of Arithmetic Textbooks.” Annual Report of the Faculty of Education, Gifu University, Educational Research 4:67-103. 
Oyabu, Chiho, and Toshiharu Sugihara. 2004. "Amish Education 4: Analysis of Geography Textbooks.” Annual Report of the Faculty of Education, Gifu University, Educational Research 6:101-26.

Oyabu, Chiho, Kazue Takamatsu, and Toshiharu Sugihara. 2003. “Amish Education 3: Analysis of History Textbooks.” Annual Report of the Faculty of Education, Gifu University, Educational Research 5:73-97.

Oyabu, Chiho, Kazue Takamatsu, and Toshiharu Sugihara. 2007. “Amish Education 5: Analysis of Reader Textbooks (Part 1).” Annual Report of the Faculty of Education, Gifu University, Educational Research 9:77-94. (In Japanese, abstract in English.)

Payne, James Irvin. 1971. "Analysis of Teacher-Student Classroom Interaction in Amish and Non-Amish Schools.” Social Problems 19(1):79-90.

Schwieder, Elmer, and Dorothy Schwieder. 1975. A Peculiar People: Iowa's Old Order Amish. Ames, IA: Iowa State University Press.

Smith, Elmer Lewis. 1961. The Amish Today: An Analysis of Their Beliefs, Behavior, and Contemporary Problems: Pennsylvania German Folklore Society.

Stoll, Joseph. 1975[1965]. “Who Shall Educate Our Children?” Pp. 16-42 in Compulsory Education and the Amish, edited by Albert Keim. Boston, MA: Beacon Press. 